\title{
Effect of mechanical treatment type on the strength of undoped single crystal indium antimonide wafers
}

\author{
Svetlana S. Kormilitsina ${ }^{1}$, Elena V. Molodtsova ${ }^{1}$, Stanislav N. Knyzev ${ }^{1}$, Roman Yu. Kozlov ${ }^{1}$, \\ Dmitry A. Zavrazhin ${ }^{1}$, Elena V. Zharikova ${ }^{1}$, Yuri V. Syrov ${ }^{2}$ \\ 1 Federal State Research and Develpment Institute of Rare Metal Industry (Giredmet JSC), 2 Elektrodnaya Str., Moscow 111524, Russia \\ 2 MIREA-Russian Technological University, 78 Vernadsky Ave., Moscow 119454, Russia \\ Corresponding author: Roman Yu. Kozlov (rykozlov@giredmet.ru)
}

Received 3 August 2020 • Accepted 5 November 2020 • Published 30 December 2020

Citation: Kormilitsina SS, Molodtsova EV, Knyzev SN, Kozlov RYu, Zavrazhin DA, Zharikova EV, Syrov YuV (2020) Effect of mechanical treatment type on the strength of undoped single crystal indium antimonide wafers. Modern Electronic Materials 6(4): 147-153. https://doi.org/10.3897/j.moem.6.4.64991

\begin{abstract}
Thin (100) wafers of single crystal undoped InSb have been strength tested by plane transverse bending. The strength of the wafers ( $\leq 800 \mathrm{~mm}$ in thickness) has been shown to depend on their mechanical treatment type. If the full mechanical treatment cycle is used (grinding + chemical polishing) the strength of the InSb wafers increases twofold (from 3.0 to $6.4 \mathrm{~kg} / \mathrm{mm}^{2}$ ). We show that the strength dependence on mechanical treatment type for (100) wafers is similar to that for (111) wafers, the strength of (111) wafers being 2 times higher. The roughness of the thin wafers after the full mechanical treatment cycle has been measured using contact profilometry. After the full mechanical treatment cycle the roughness of the InSb wafers $R_{\mathrm{a}}$ decreases from 0.6 to $0.04 \mathrm{~mm}$ leading to general surface smoothening. We have compared the strength and roughness between (100) InSb and GaAs wafers. The roughness of InSb and GaAs wafers after the full mechanical treatment cycle decreases significantly: by 10 times for InSb due to the general surface smoothening and by 3 times for GaAs ( $R_{\mathrm{z}}$ from 2.4 to $0.8 \mathrm{~mm}$ ) due to a reduction of the peak roughness component. The full mechanical treatment cycle increases the strength of InSb wafers by removing damaged layers through the sequence of operations and reducing the risk of mechanical damage development.
\end{abstract}

\section{Keywords}

indium antimonide, Czochralsky method, thin wafers, yield strength, mechanical treatment, chemical polishing, crystallographic orientation, wafer roughness.

\section{Introduction}

Single crystal indium antimonide is still among the main semiconductors used for the fabrication of electronic components in a broad application field of solid state electronics, i.e., optoelectronics. This material is used for the fabrication of linear and array photocells operated in the $3-5 \mathrm{~mm}$ wavelength range that are employed as photosensitive elements in heat vision systems [1]. These heat vision systems find general application in multiple fields of economy (medicine, materials science, environmental pollution monitoring etc.). Indium antimonide focal arrays are used in special purpose devices installed in airborne navigation and precision targeting systems, antiaircraft infrared tracking heads, marine infrared detectors and unmanned aircrafts.

Indium antimonide has a special position in the range of $A^{\mathrm{III}} B^{\mathrm{V}}$ semiconductors. Its lowest crystallization tem- 
perature, narrow band gap, high carrier mobility, relatively simple technology of high purity single crystals with high structural perfection and good homogeneity of electrical parameters show good promise of this material for many potential applications. Currently indium antimonide is used in field effect transistors with fast response and low power consumption which is important for digital devices [2]. Research endeavors are underway to develop indium antimonide nanowire arrays in regular pores of anodic aluminum oxide with various metallization contacts which can be used for the fabrication of $\mathrm{THz}$ range electromagnetic generators [3].

Analysis of advertizing announcements [4-8] suggests that currently the main products in international and domestic markets are not bulk single crystals but 450 $600 \mathrm{~mm}$ thick polished epi-ready wafers for the synthesis of complex homo- and heteroepitaxial structures. Indium antimonide epitaxial layers are often grown on (100) or (111) oriented wafers [9]. The growth of single crystals in the [111] direction always causes the edge effect (inhomogeneity of electrical properties in a channel-shaped central crystal zone along the whole crystal) [10]. For the avoidance of this effect indium antimonide single crystals were earlier grown in the [211] direction and the required orientation wafers were cut from the single crystals at a 19 arc deg angle for the (111) orientation and at a 59 arc deg angle for the (100) orientation. The loss of material for cutting was at least $50 \%$. Obviously it is more economically advantageous to grow indium antimonide single crystals in the [100] crystallographic direction which among other advantages ensures high structural perfection of the single crystals [11]. Similar results have been obtained for other $A^{\mathrm{III}} B^{\mathrm{V}}$ semiconductors (GaSb, GaAs, InAs) [12].

The epi-ready indium antimonide wafer technology is developed quite poorly in Russia and its implementation requires profound studies of individual mechanical properties of this semiconductor compound that differ significantly from those of other $A^{\mathrm{III}} B^{\mathrm{V}}$ semiconductors. Single crystal calibration and dicing operations, mechanical and chemomechanical treatment of wafers are low-temperature processes which still affect the final product quality (wafers) and hence influence the product yield [13]. It has been reported [14, 15] that each post-cutting wafer treatment operation is aimed at removing defect layers produced by the previous treatment operation and thus an undamaged wafer surface layer is eventually achieved. The modes of each subsequent mechanical treatment operations will differ substantially between $A^{\mathrm{III}} B^{\mathrm{V}}$ semiconductors due to the difference in the mechanical properties and strength of these compounds.

The trend to increase single crystal diameter (and hence wafer diameter) is common for all the $A^{\mathrm{III}} B^{\mathrm{V}}$ semiconductors due to the permanent growth of opto-, micro- and nanoelectronics markets. The structural perfection and geometry requirements to the wafer surface are increasingly stringent. Therefore improving the mechanical and chemomechanical treatment processes for large-diameter wafers requires authentic data on the depth and structure of the damaged layer and the geometry of the wafers after each treatment step, as well as their dependence on the process parameters and intrinsic properties of specific materials.

An important specific feature of indium antimonide is its extreme brittleness which complicates any chemomechanical treatment of the crystals, causing cracks and eventual destruction. This problem is aggravated for large diameter crystals. It originates from thermal elastic stresses induced during crystal growth and subsequent cooling. In [100] InSb crystals the axial temperature gradient near the crystallization front is large, reaching 35-40 deg/cm $[16,17]$. The crystallization front in these crystals has a typical "saucer" shape with a convexity towards the melt, caused by the small radial temperature gradient at the crystallization front. The experimental dislocation density in [100] InSb crystals is $\sim 50 \mathrm{~cm}^{-2}$, being one order of magnitude lower as compared with that of crystals grown in the [211] direction. Since dislocation formation in the crystals is induced by shear stresses in the slipping plane one can assume that for crystals grown in the [100] direction the shear stresses in the [111] $<110>$ slipping system are small and thus the resultant dislocation density in the crystal should be low. These shear stresses cannot compensate the thermal elastic stresses induced during crystal growth and hence the crystal remains stressed and this complicates its cutting into wafers and further wafer mechanical treatment.

The aim of this work is to study the effect of different mechanical treatment types (cutting, grinding and etch polishing) on the strength of undoped single crystal indium antimonide wafers.

\section{Experimental}

We grew indium antimonide single crystals using a two-stage Czochralsky process in static vacuum [17]. At the first stage we synthesized indium antimonide from the raw components (7N purity In and $\mathrm{Sb}$ ) and grew the polycrystal for seed. At the second stage we grew a [100] oriented single crystal with the preset properties from the InSb polycrystals. To obtain $\varnothing 55-60 \mathrm{~mm}$ single crystals with a low dislocation density we formed an inverse cone at the final growth stage. Then to reduce the thermal plastic deformations in the single crystals we heat treated the crystals in the growth furnace in an experimentally selected mode.

To measure the electrical parameters and the dislocation density of the crystals we cut out (100) wafers perpendicular to the growth axis from the top and bottom parts of the crystals.

For dislocation pit etching we ground the wafers sequentially with M14 and M7 powders and chemically etched first in CP-4 polishing etchant and then in $\mathrm{HCl}_{\text {conc. }}: \mathrm{H}_{2} \mathrm{O}_{2}=2: 1$ selective etchant for $5 \mathrm{~min}$ [18].

We monitored the dislocation density distribution under an optical microscope and counted etch pits following the 
dislocation density measurement method for InSb crystals, i.e., by taking nine fields located within two diameters arranged at a 90 arc deg angle relative to each other [19]. The dislocation densities in the top and bottom parts of the crystals were within $50 \mathrm{~cm}^{-2}$ and did not alter after the introduction of other structural defects (lamels or twins).

We measured the electrical parameters of the undoped indium antomonide single crystals using the Van der Pau method [20] at $77 \mathrm{~K}$ for the same wafers.

The $77 \mathrm{~K}$ carrier concentration in the as-grown crystals was $2 \cdot 10^{14}-3 \cdot 10^{15} \mathrm{~cm}^{-3}$, the electron mobility being at least $2 \cdot 10^{5} \mathrm{~cm}^{2} /(\mathrm{V} \cdot \mathrm{s})$. These figures agree with those for undoped indium antimonide.

We calibrated the cylindrical part of the crystal on an OD grinding machine to $\varnothing 50.8 \mathrm{~mm}$ and then oriented it on an $X$-ray diffractometer to exactly locate the (100) planes. Then we placed the crystal into a wire cutting machine and cut it into $\sim 830 \mathrm{~mm}$ thick wafers. After cutting we rinsed the wafers in a water solution of washing agents, dried and took samples for mechanical strength tests and control of damaged layer parameters.

For the mechanical strength tests we used the plane transverse bending method [21] for which the specimen is statically loaded throughout the entire test until fracture.

Figure 1 shows schematic of the plane transverse bending method and bending moment curves for three-point (Fig. $1 a$ ) and four-point (Fig. $1 \mathrm{~b}$ ) loading patterns.

For the three-point loading pattern (Fig. $1 a$ ) the most stressed specimen points A and B are under uniaxial stresses. This test includes the measurement of the load $P$ and the flexure $w$ in the specimen center. For a rectangular specimen the maximum fracture stress $\sigma_{\max }\left(\mathrm{kg} / \mathrm{mm}^{2}\right)$ is as follows:

$$
\sigma_{\max }=\frac{1,5 p l}{b h^{2}}
$$

where $p$ is the load in $\mathrm{kg}$, and $l, b$ and $h$ are the linear dimensions (length, width and thickness) of the specimen, respectively, in $\mathrm{mm}$.
For the four-point loading pattern (Fig. $1 \mathrm{~b}$ ) the bending moment curve has a flat peak plateau corresponding to the maximum tensile stress $\sigma_{\max }$ at the BB' section of the specimen's bottom stressed side. For a rectangular specimen we have

$$
\sigma_{\max }=\frac{p l}{b h^{2}}
$$

To measure the mechanical strength with the plane transverse bending method we cut the wafers into rectangular specimens $3-14 \mathrm{~mm}$ in length, $1-6 \mathrm{~mm}$ in width and $0.5-0.8 \mathrm{~mm}$ in thickness. Then we ground the specimens with $\mathrm{M} 7$ powder and treated with $\mathrm{CP}-4$ polishing etchant. Thus we made 4 specimen batches $\sim 25$ specimens in each which differed by surface treatment type (as-cut, as-ground, as-polished and as-ground + polished) and mechanically tested each batch with the plane transverse bending method. The specimen load was from 0.25 to $2 \mathrm{~kg}$. The yield strength (brittle fracture stress) formula used was as follows:

$$
\tilde{\sigma}_{\mathrm{av}}=\frac{1}{n} \sum_{i=1}^{i=n} \sigma_{\max _{i}},
$$

where $\mathrm{n}$ is the number of specimens.

The RMS measurement error was calculated as follows:

$$
\Delta \tilde{\sigma}_{\mathrm{av}}=\sqrt{\frac{\sum_{i=1}^{n}\left(\sigma_{\max _{i}}-\tilde{\sigma}_{\mathrm{av}}\right)^{2}}{n-1}} .
$$

Along with the strength we measured the surface roughness parameters $R_{\mathrm{a}}$ and $R_{\mathrm{z}}$ for differently treated surfaces of the remaining parts of the wafers using contact profilometry [22] and the applied software. The instrument measurement error was within $1 \%$.

Surface roughness is defined as the total unevenness of the surface measured with relatively small steps. In order to differentiate between surface roughness and other unevenness having a relatively large scale (shape deviation
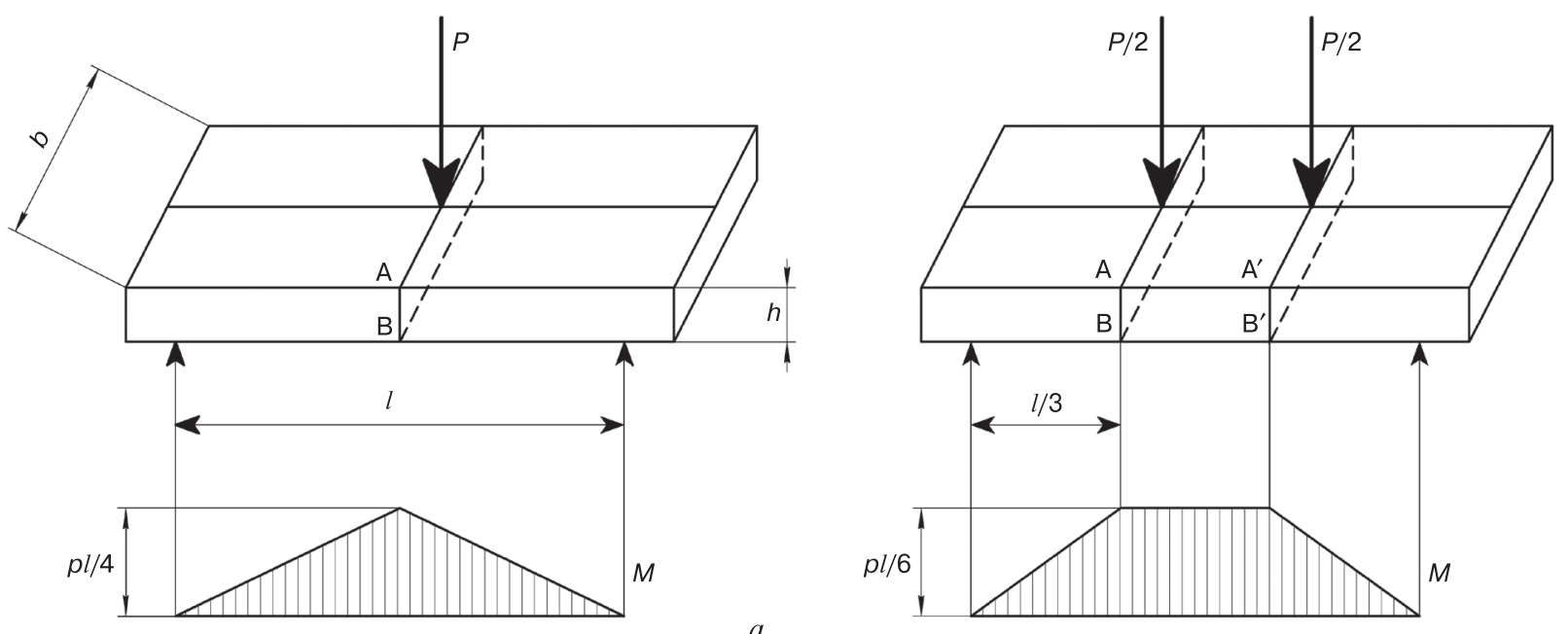

Figure 1. Specimen loading patterns $((a)$ three-point and $(b)$ four-point) and bending moment curves for plane transverse bending method. 
and waviness), roughness is measured within a relatively small area the length of which is referred to as the base length. Surface roughness is evaluated from unevenness profiles obtained by specimen surface sectioning with a plane. Example of a surface roughness profile is shown in Fig. 2 [23]. The surface roughness values are measured counting from the same origin taken to be the profile average line, i.e., the base line. Roughness is typically quantified using three main parameters:

$-R_{\mathrm{a}}$ : arithmetical mean of absolute values of profile deviation within the base length, $\mathrm{mm}$;

$-R_{\mathrm{z}}$ : sum of average absolute values of heights for five highest profile peaks and depths for five deepest profile valleys within the base length, $\mathrm{mm}$;

$-R_{\max }$ : highest profile unevenness within the base length, $\mathrm{mm}[24]$

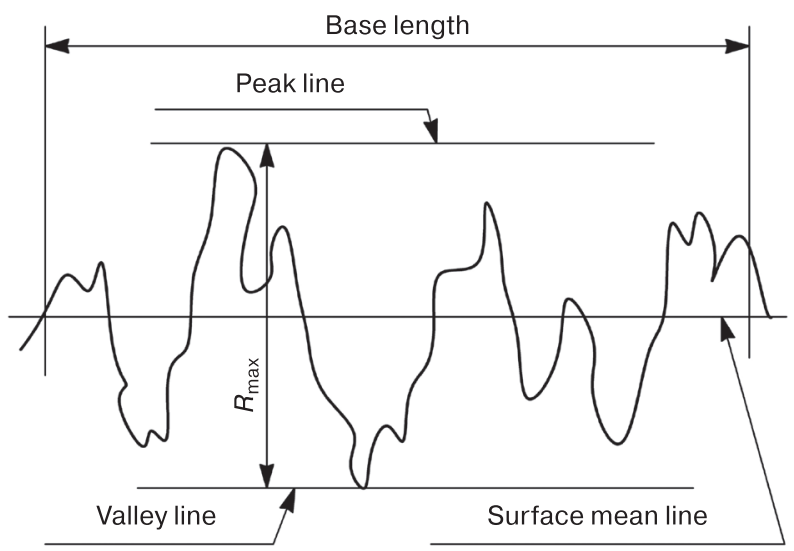

Figure 2. Surface profile obtained with a profilometer.

\section{Results and discussion}

The plane transverse bending strength test method is destructive and does not allow reusing the specimens. Each test specimen batch included 25 rectangular specimens with $10 \times 5 \times 0.8 \mathrm{~mm}$ dimensions. The first batch specimens were as-cut, those of the second batch were as-ground, the third batch consisted of as-polished specimens and the fourth one consisted of as-ground + polished specimens. All the four rectangular specimen batches were plane transverse bent, with the fracture stress increasing as we changed from rough treated specimens to finer treated ones.

Figure 3 shows plane transverse bending strength measurement data for indium antimonide specimens depending on treatment type for three- and four-point loading patterns.

As can be seen from Fig. $3 a$, the average mechanical strength of the as-cut InSb specimens (without further mechanical treatment) for three-point loading pattern is $\sigma_{\mathrm{av}}=3.0 \pm 0.9 \mathrm{~kg} / \mathrm{mm}^{2}$. Grinding or polishing of these specimens slightly increases their strength, with the increase being within the measurement error for the as-cut specimens. The strength increases considerably in the
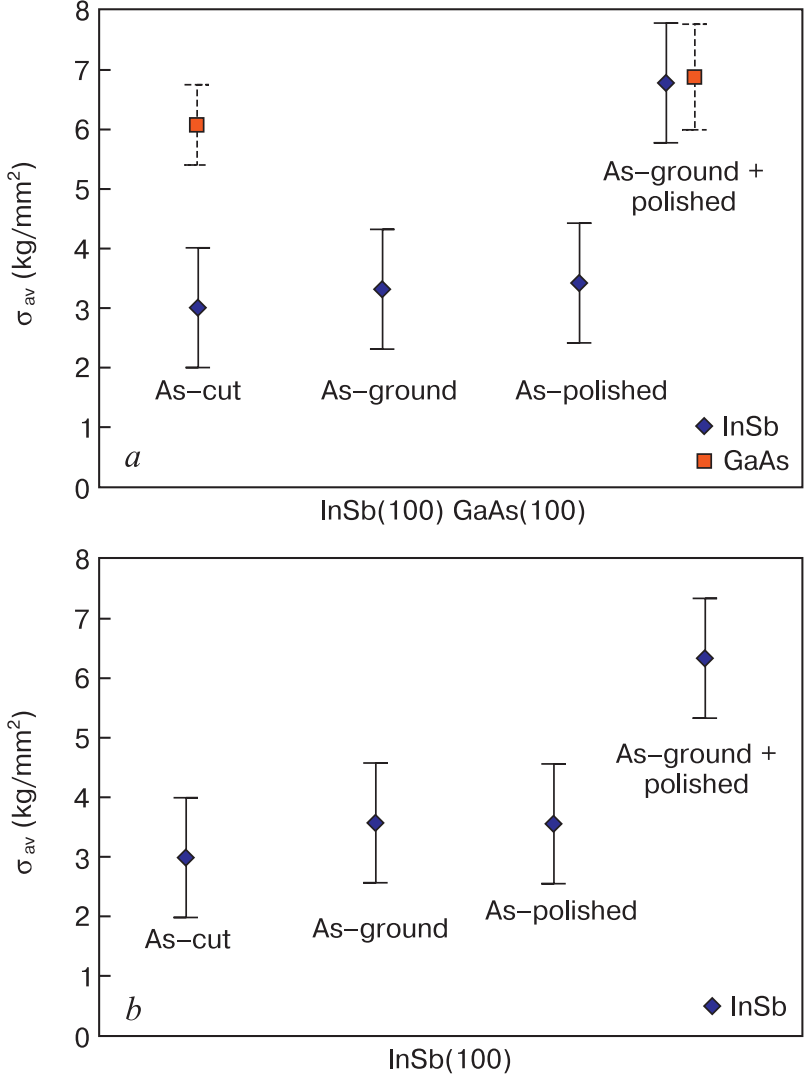

Figure 3. Yield strength of (100) single crystal indium antimonide specimens after different types of mechanical treatment: (a) three-point loading pattern; (b) four-point loading pattern

full-cycle mechanically treated (ground + polished) specimens, the average strength being $\sigma_{\text {av }}=6.8 \pm 0.9 \mathrm{~kg} / \mathrm{mm}^{2}$.

Figure $3 b$ shows that the yield strength measured with the four-point loading pattern increases for the full-cycle mechanically treated (ground + polished) specimens by analogy with the three-point loading pattern data. The yield strength of these specimens is $\sigma_{\mathrm{av}}=6.4 \pm 0.9 \mathrm{~kg} / \mathrm{mm}^{2}$ which can be considered equal to $\sigma_{a v}$ for the three-point loading pattern within the measurement error. The yield strengths obtained for the two loading patterns agree well between each other and suggest an increase in the strength of the full-cycle mechanically treated specimens.

By way of comparison we measured the mechanical strength of as-cut and as-ground + polished specimens of low-doped GaAs $\left(n=2 \cdot 10^{16} \mathrm{~cm}^{-3}\right)$ with the (100) orientation using the three-point loading pattern. The polishing etchant composition for the GaAs specimens was $\mathrm{H}_{2} \mathrm{O}: \mathrm{H}_{2} \mathrm{O}_{2}: \mathrm{H}_{2} \mathrm{SO}_{4}=1: 1: 3$. Figure $3 a$ also shows average yield strengths of the GaAs specimens. It can be seen from Fig. $3 a$ that the strength of the as-cut GaAs specimens is higher than that of the InSb ones. The strength of the full-cycle mechanically treated InSb specimens is almost the same as that of the GaAs specimens which in turn depends but slightly on treatment type.

The data illustrated in Fig. 3 suggest that the strength of thin $(\leq 800 \mathrm{~mm})$ wafers for different $3-5$ compounds is an individual parameter of the materials and depends on mechanical treatment in a specific manner. The higher strength 
of the as-cut GaAs specimens $\left(\sigma_{\mathrm{av}}=6.1 \pm 0.8 \mathrm{~kg} / \mathrm{mm}^{2}\right)$ seems to be caused by the low level of residual stresses and the sufficiently high dislocation density $\left(N_{\mathrm{d}}=2 \cdot 10^{4} \mathrm{~cm}^{-2}\right)$ in the crystal, for which the dislocation formation energy is far lower than the thermal stress energy in the growing crystal. Therefore any additional treatments of the GaAs wafers cannot introduce more defects or develop conditions for defect formation. The low strength of the as-cut InSb specimens can be due to the high residual stresses and the very low dislocation density $\left(\leq 50 \mathrm{~cm}^{-2}\right)$ in the crystal. The full mechanical treatment cycle considerably increases the strength of the InSb specimens (approx. twofold) while the strength of the GaAs specimens increases but slightly. It is safe to assume that the presence of multiple microcracks after InSb crystal calibration and wafer cutting may lead to their development after different chemomechanical polishing and chemodynamical polishing treatments. Therefore increasing the strength of InSb specimens requires preliminary grinding of the as-cut specimens so as to minimize the damaged layer and further polishing in CP-4 fast etchant to completely remove the damaged layers. However fast etching in CP-4 is not used for InSb wafer preparation in device technologies while polishing in slow etchants develops microcracks. One should therefore pay more attention to specimen grinding with fine powders.

The strength of GaAs does not depend on mechanical treatment so critically but sequential removal of damaged layers is still a necessary condition for the production of undamaged surfaces and hence high-quality device structures. This is confirmed by our wafer surface roughness data (see below).

Figure 4 shows yield strength data for (111) InSb and GaAs wafers borrowed from literature [21].

As follows from Figs 3, 4, the experimental strengths of the (100) wafers after different treatments differ substantially from those of the (111) oriented wafers after similar mechanical treatments. Noteworthy the strength of the (100) wafers is 2 or more times lower than that of the (111) wafers. This difference in the strength between differently oriented wafers is typical of both InSb and GaAs. Data on the dependence of the strength of (111) oriented wafers

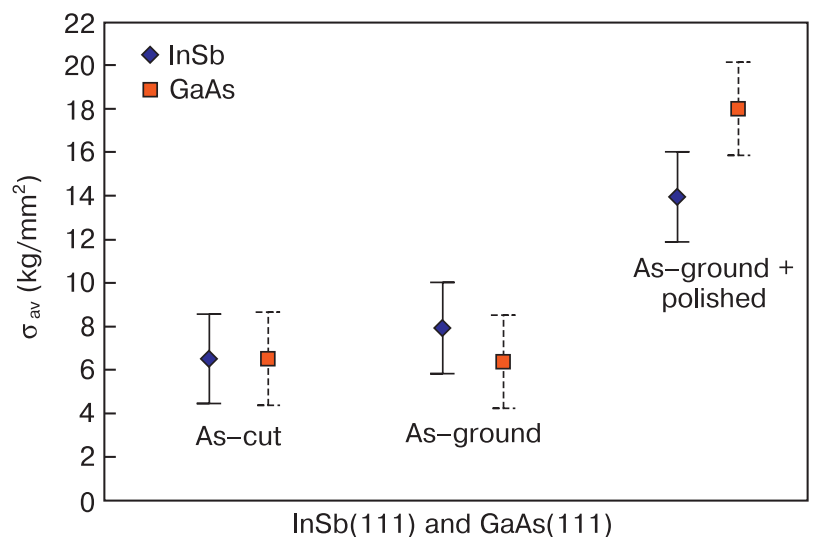

Figure 4. Yield strength of (111) single crystal indium antimonide specimens after different types of mechanical treatment for three-point loading pattern [21] on their treatment type [21] also suggest that the wafer strengths increase considerably after the full mechanical treatment cycle, by analogy for the (100) wafers. Presumably the high strength of the (111) oriented wafers in comparison with the (100) ones is caused by the closest packing of the (111) planes in the lattices of 3-5 compounds.

We also measured the surface roughness of the (100) InSb wafers as-cut, as-ground and after the full mechanical treatment cycle. For comparison we also measured the roughness of GaAs wafers. The Table 1 below summarizes the roughness data for the InSb and GaAS wafers.

The data summarized in the Table 1 suggest that the roughness of the as-cut (100) wafers (the $R_{\mathrm{a}}$ and $R_{\mathrm{z}}$ parameters) differ significantly: the roughness of the InSb wafers is $25 \%$ higher than that of the GaAs wafers. Grinding

Table 1. Roughness of InSb and GaAS wafers for different mechanical treatments.

\begin{tabular}{|c|c|c|c|c|c|}
\hline \multicolumn{6}{|c|}{ Wafer treatment type } \\
\hline \multicolumn{2}{|c|}{ As-cut } & \multicolumn{2}{|c|}{ As-ground } & \multicolumn{2}{|c|}{ As-ground + polished } \\
\hline$R_{\mathrm{a}}, \mathbf{m m}$ & $R_{z}, \mathbf{m m}$ & $R_{\mathrm{a}}, \mathbf{m m}$ & $R_{z}, \mathbf{m m}$ & $R_{\mathrm{a}}, \mathbf{m m}$ & $R_{z}, \mathbf{m m}$ \\
\hline \multicolumn{6}{|c|}{$\mathrm{InSb}$} \\
\hline 0.6 & 3 & 0.4 & 2.6 & 0.04 & 0.17 \\
\hline 0.7 & 3.2 & 0.4 & 2.3 & 0.03 & 0.13 \\
\hline 0.6 & 3.1 & 0.4 & 2.4 & 0.03 & 0.12 \\
\hline 0.6 & 3 & - & - & 0.04 & 0.15 \\
\hline 0.6 & 3.5 & - & - & 0.05 & 0.18 \\
\hline \multicolumn{6}{|c|}{ GaAs } \\
\hline 0.3 & 2.4 & 0.4 & 1.8 & 0.16 & 0.8 \\
\hline 0.4 & 2.3 & 0.4 & 1.8 & 0.14 & 0.7 \\
\hline 0.4 & 2.4 & 0.4 & 1.9 & 0.19 & 0.8 \\
\hline 0.5 & 2.4 & 0.4 & 1.7 & 0.19 & 0.9 \\
\hline
\end{tabular}

of the as-cut specimens reduced the roughness of the InSb wafers by approx. $25 \%$ (both the $R_{\mathrm{a}}$ and $R_{\mathrm{z}}$ parameters), but for the GaAs wafers the $R_{\mathrm{a}}$ roughness parameter does not change as a result of grinding whereas the $R_{\mathrm{z}}$ parameter also decreased by $25 \%$. It seems that grinding of the InSb wafers leads to general surface smoothening whereas grinding of GaAs only removes the highest peaks of the roughness profile. This can be attributed to different hardnesses of these compounds (the microhardness of indium antimonide is 3.8 while that of gallium arsenide is 4.5 ). The roughness decreased substantially as a result of etching of both $\mathrm{InSb}$ and GaAs as-ground specimens. Both roughness parameters $R_{\mathrm{a}}$ and $R_{\mathrm{z}}$ of the compounds decreased by approx. one order of magnitude. Noteworthy InSb and GaAs were treated with different literary reported etchants. The thickness of the InSb damaged layers completely removed after the full treatment cycle was $\sim 300-350 \mathrm{~mm}$ while the thickness of the completely removed GaAs damaged layers was $\sim 150-200 \mathrm{~mm}$. For the InSb specimens after the full mechanical treatment cycle the surface roughness parameters $R_{\mathrm{a}}$ and $R_{\mathrm{z}}$ were $\sim 0.04$ and $0.16 \mathrm{~mm}$, respectively, and for the GaAs specimens they were $\sim 0.16$ and $0.8 \mathrm{~mm}$, respectively. Thus the full mechanical treatment cycle of the wafers not only increases their strength but also almost completely removes the damaged layers through the sequence of operations without causing the development of mechanical damage induced during crystal calibration and 


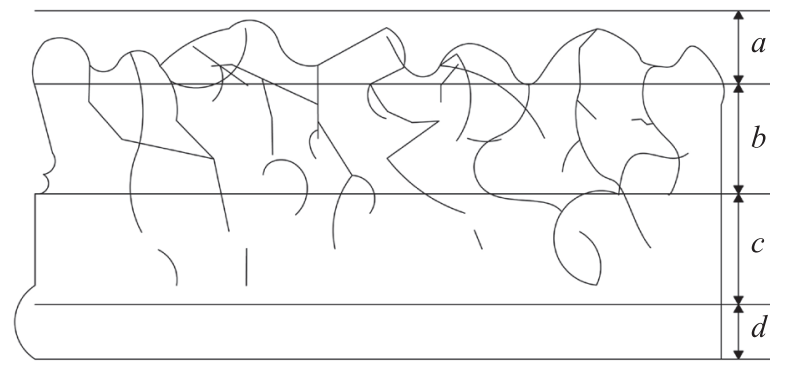

Figure 5. Superficial layer of as-cut single crystal: (a) roughness layer, $(b)$ crack layer, $(c)$ deformed layer and $(d)$ undamaged single crystal structure.

wafer cutting. Further chemical polishing of the wafers in special etchants produces undamaged surface layers and eventually provides for epitaxy-ready molecular surfaces. Figure 5 shows the superficial layer structure of an as-cut single crystal [25]. It is safe to assume that the full mechanical treatment cycle of thin GaAs wafers mainly affects their surface roughness and has but a little effect on the strength of the wafers since the residual plastic deformations in the material are small and the thickness of the damaged layers is smaller compared with that for InSb.

\section{Conclusion}

The strength of thin (100) single crystal undoped indium anitmonide wafers was studied using the plane transverse bending method. The strength of the wafers $(\leq 800 \mathrm{~mm}$ in thickness) proved to depend on their treatment. Separate

\section{References}

1. Grinchenko L.Ya., Ponomarenko V.P., Filachev A.M. Current state and outlookof Ir photoelectronics development. Prikladnaya fizika, 2009; (2): 57-2. (In Russ.)

2. Intel and QinetiQ Collaborate on Transistor Research. URL: http:// www.intel.com/pressroom/arihive/releass/2005/20050208corp.htm (accessed: 28.10.2020).

3. Obukhov I., Gorokh G.G., Lozovenko A., Smirnova E. Matrices of indium antimonide nanowires and their applications in microwave generators. Nanoindustry, 2017; 77(6): 96-108. (In Russ.). https:// doi.org/10.22184/1993-8578.2017.77.6.96.108

4. Electronics and Materials Corporation Limited. URL: http://eandmint.co. jp/eng/wafer/product_detail/product_insb.html (accessed: 28.10.2020).

5. Trail: Wafer Technology Ltd. URL: http://www.wafertech.co.uk (accessed: 28.10 .2020$)$.

6. MTI Corporation. URL: http://www.mtixtl.com/ (accessed: 28.10.2020)

7. Galaxy Compound Semiconductors, Inc. URL: http://www.galaxywafer.com/ (accessed: 28.10.2020).

8. Xiamen Powerway Advanced Material Co, Ltd. URL: https://www. powerwaywafer.com/compound-semiconductor/insb-wafer.html (accessed: 28.10.2020).

9. Akchurin R.Kh., Marmalyuk A.A. MOS-gidridnaya epitaksiya v tekhnologii materialov fotoniki $i$ elektroniki [MOS hydride epitaxy in grinding and etching increase the strength of the wafers but slightly. The full mechanical treatment cycle with etching in CP-4 fast polishing etchant that etches microcracks and surface defects faster than the crystal matrix increases the strength of the InSb wafers twofold (from 3.0 to $6.4 \mathrm{~kg} / \mathrm{mm}^{2}$ ). The dependence of wafer strength on mechanical treatment type for the (100) wafers is similar to the respective dependence for the (111) wafers but the strength of the (111) wafers is twice as high as that of the (100) wafers $\left(6.2 \mathrm{~kg} / \mathrm{mm}^{2}\right)$.

The roughness of the wafers after different mechanical treatment stages was studied using contact profilometry. After the full mechanical treatment cycle the roughness of the InSb wafers decreased substantially $\left(R_{\mathrm{a}}\right.$ from 0.6 to $0.04 \mathrm{~mm}$ ) causing general surface smoothening.

The strength and roughness of the InSb wafers were compared with those of GaAs wafers. The strength of the as-cut GaAs wafers $\left(6 \mathrm{~kg} / \mathrm{mm}^{2}\right)$ is twice as high as that of the as-cut InSb wafers $\left(3 \mathrm{~kg} / \mathrm{mm}^{2}\right)$ and increases but slightly as a result of the full mechanical treatment cycle. The roughness of the GaAs and $\mathrm{InSb}$ wafers after the full mechanical treatment cycle decreases substantially: by 10 times for InSb due to general surface smoothening and by 3 times for GaAs $\left(R_{\mathrm{z}}\right.$ from 2.4 to $0.8 \mathrm{~mm}$ ) due to a reduction of the peak roughness component.

Thus the full mechanical treatment cycle of InSb wafers increases their strength and reduces their surface roughness by removing the damaged layers through the sequence of operations and reducing the risk of mechanical damage development. photonics and electronics materials technology]. Moscow: Tekhnosfera, 2018: 488. (In Russ.)

10. Gorelik S.S., Dashevskii M.Ya. Materialovedenie poluprovodnikov $i$ dielektrikov [Materials science of semiconductors and dielectrics]. Moscow: MISiS, 2003: 480. (In Russ.)

11. Ezhlov V.S., Milvidskaya A.G., Molodtsova E.V., Kolchina G.P., Mezhennyi M.V., Resnick V.Y. Investigation on the properties of large [100]-oriented InSb single crystals grown by Czohralski method. Izvestiya Vysshikh Uchebnykh Zavedenii. Materialy Elektronnoi Tekhniki = Materials of Electronics Engineering, 2012; (2): 13-17. (In Russ.). https://doi.org/10.17073/1609-3577-2012-2-13-17

12. Milvidskii M.G. Poluprovodnikovye materialy v sovremennoi elektronike [Semiconductor materials in modern electronics]. Moscow: Nauka, 1986: 143. (In Russ.)

13. Boltar K.O., Vlasov P.V., Eroshenkov V.V., Lopuhin A.A. Research of photodiodes with a leakage current in the InSb FPA. Prikladnaya fizika, 2014; (4): 45-50. (In Russ.)

14. Biryukov E.N., Khokhlov A.I., Teplova T.B., Lapshin I.V. Impact of nonuniform fractured surface layer of processed brittle material plates on end product quality. Mining Informational and Analytical Bulletin (Scientific and Technical Journal), 2018; (8): 26-35. (In Russ.). https://doi.org/10.25018/0236-1493-2018-8-0-26-35 
15. Zakharov B.G. Issledovanie i razrabotka tekhnologii i sposobov polucheniya podlozhek $i$ ehpitaksial'nykh sloev poluprovodnikovykh materialovs vysokim strukturnym sovershenstvom [Research and development of technology and methods for producing substrates and epitaxial layers of semiconductor materials with high structural perfection]. Diss. ... Dr. Sci. (Eng.). Kaluga, 1984: 423. (In Russ.)

16. Milvidskii M.G., Osvenskii V.B. Strukturnye defekty v monokristallakh poluprovodnikov [Structural defects in single crystals of semiconductors]. Moscow: Metallurgiya, 1984: 256. (In Russ.)

17. Patent 2482228 (RF) Sposob polucheniya krupnogabaritnykh kristallov antimonida indiya InSb [A method of obtaining large crystals of indium antimonide InSb]. V.S. Ezhlov, A.G. Mil’vidskaya, E.V. Molodtsova G.P. Kolchina, M.V. Mezhennyi, V.Ya. Reznik, 2012. (In Russ.)

18. Fost J. Travlenie poluprovodnikov [Semiconductor etching]. Moscow: Mir, 1965: 382. (In Russ.)

19. Amelinks S. Metody pryamogo nablyudeniya dislokatsii [Direct observation of dislocations]. Moscow: Mir, 1968: 438. (In Russ.)

20. van der Pauw L.J. A method of measuring specific resistivity and Hall effect of discs of arbitrary shape. Philips Res. Rep., 1958;
13: 220-224. URL: http://electron.mit.edu/ gsteele/vanderpauw/ vanderpauw.pdf

21. Kontsevoi Yu.A., Litvinov Yu.M., Fattakhov Eh.A. Plastichnost' $i$ prochnost' poluprovodnikovykh materialov i struktur [Plasticity and strength of semiconductor materials and structures]. Moscow: Radio i svyaz, 1982: 239 p. (In Russ.)

22. Mal'kov O.V., Litvinenko A.V. Izmerenie parametrov sherokhovatosti poverkhnosti detali [Measurement of the surface roughness parameters of the part]. Moscow: Bauman MSTU, 2012: 22. (In Russ.)

23. Khusu A.P., Vitenberg Yu.R., Pal'mov V.A. Sherokhovatost'poverkhnostei (teoretiko-veroyatnostnyi podkhod) [Surface roughness (probability-theoretical approach)]. Moscow: Nauka, 1975: 344. (In Russ.)

24. Nazarov Yu.F., Shkilko A.M., Tikhonenko V.V., Kompaneets I.V. Methods of research and control of surface roughness of metals and alloys. Fizicheskaya inzheneriya poverkhnosti, 2007; 5(3-4): 207-216. (In Russ.)

25. Karban V.I., Borzanov Yu.I. Obrabotka monokristallov v mikroehlektronike [Processing of single crystals in microelectronics]. Moscow: Radio i svyaz, 1988: 103. (In Russ.) 